\title{
IMPACT OF TREATMENT WITH DIRECT ACTING ANTIVIRAL AGENTS (DAAS) ON MIXED CRYOGLOBULINEMIA OF HCV EGYPTIAN PATIENTS
}

\author{
By
Karim S. El-Noemany, Mohamed H. El-Nadry, Sayed F. Mohamed and Mohamed M. Abd El-Halim \\ Hepato-Gastroenterology and Infectious Diseases Department, Al-Azhar University \\ (Cairo) \\ E-mail: $\underline{\text { dr_kareemn@yahoo.com }}$
}

\begin{abstract}
Background: Up to $74 \%$ of patients affected by HCV have HCV-related extrahepatic manifestation (EHMs) including autoimmune diseases, mixed cryoglobulinemia (MC) and non-Hodgkin lymphomas (NHL).Objective: To study the impact of treatment with direct acting antiviral agents (DAAS) on mixed cryoglobulinemia of HCV Egyptian patients.

Patients and methods: This study was carried out in cooperation between the Hepato-gastroenterology and Infectious Diseases Department, Al-Azhar University, Cairo, and Shebin Elkom Fever Hospital from March 2018 to December 2019. The study included 80 patients with HCV-related EHMs including cutaneous (30 patients), musculoskeletal (30 patients) and renal manifestation (20 patients). All patients were naïve to treatment with DAAs (Sofosbuvir/Daclatasvir \pm Ribavirin regimen).

Results: Purpuric papules of the lower extremities were the most frequent cutaneous lesion (80\%), and arthralgia was the most frequent in musculoskeletal manifestations (90\%). Diffuse membranoproliferative glomerulonephritis was the most frequent lesion in patients, with renal manifestations (90\%). Significant increase occurred in the serum cryoglobulin levels and RF, with significant decreasein C3 and C4 serum levels in all groups. There were significant decrease in the mean cryoglobulin levels from positive to negative, with significant decline in RF concentrations, and rise in $\mathrm{C} 3$ and $\mathrm{C} 4$ serum levels approaching the normal values. There were improvements in the presenting HCV-MC clinical manifestations in variable degrees, rangingfrom $71.42 \%$ in patients with glomerulonephritis to $98.4 \%$ in patients with purpura. Eightyseven percent of the included patients showed complete response (clinical, virologicaland immunological recovery), and 13\% showed partial response (virological and immunological recovery without clinical improvement of cryoglobulinemia associated manifestations).
\end{abstract}

Conclusion: DAAs, in the form of Sofosbuvir/Daclatasvir \pm Ribavirin regimen, were treatment of choice for $\mathrm{HCV}$ infection, and considered in cases of HCV-MC as they were associated with clinical improvement in most patients.

Keywords: Directly acting antiviral drugs, mixed cryoglobulinemia, HCV.

\section{INTRODUCTION}

Mixed cryoglobulinemia

(MC)

vasculitis (Cryovas) is a small vessel vasculitis involving mainly the skin, the joints, the peripheral nerve system and the kidneys. HCV infection is the cause of Cryovas in about $80 \%$ of cases. The disease expression is variable, ranging from mild symptoms (purpura, arthralgia) 
to fulminant life-threatening complications (glomerulonephritis, widespread vasculitis). Skin is the most frequently involved target organ: palpable purpura, chronic cutaneous ulcers, Raynaud's phenomenon, acrocyanosis, which may evolve to digital ulcerations (Terrier and Cacoub, 2013).

Pegylated interferon alfa (INF-alfa) combined with ribavirin has demonstrated efficacy in patients with cryoglobulinemia associated with HCV infection, and efficacy in patients with chronic myelogenous leukemias and low-grade lymphomas has been reported. The details of therapy and the recommended approach vary based on the clinical setting and expert opinion should be sought (Mazzaro et al., 2011).

Treatment with direct-acting. antivirals not only cures people of hepatitis $\mathrm{C}$, but can also rapidly reduce the severity of one of the most troublesome extra hepatic manifestations of the disease, Although studies of direct-acting antivirals show that newly-licensed combinations can cure hepatitis C in 90 to $95 \%$ of people, there is less information about the extent to which curing hepatitis $\mathrm{C}$ leads to improvements in the health of the liver or resolution of symptoms such as cryoglobulinemia (Ramos-Casals et al., 2017).

The present study aimed to study the impact of treatment with direct acting antiviral agents (DAAS) on mixed cryoglobulinemia of HCV Egyptian patients.

\section{PATIENTS AND METHODS}

This study was carried out in cooperation between the HepatoGastroenterology and Infectious Diseases
Department, Al-Azhar University, Cairo, and Shebin Elkom Fever Hospital after the approval of the ethical committee and obtaining consent from all the enrolled patients. The study period was from March 2018 to December 2019. Six hundred thirty patients with chronic hepatitis $\mathrm{C}$ (CHC) were clinically examined and investigated for variable manifestations of mixed cryoglobulinemia related $\mathrm{HCV}$. $\mathrm{CHC}$ was diagnosed by laboratory test (PCR quantitative for HCV-RNA). The inclusion criteria was evidence of $\mathrm{HCV}$ infection in the form of a positive test for anti-HCV antibodies and confirmed by PCR for HCV RNA, age from 18-75 years and systemic disorders in which cutaneous vasculitis, arthralgia or glomerulonephritis associated HCV infection. All indications of treatment of $\mathrm{HCV}$ patients according to the Egyptian protocol of therapy. We excluded in this study conditions that might be associated with secondary cryoglobulinemia such as hematologic tumors, autoimmune disorders, and acute or chronic infectious disease not related to $\mathrm{HCV}$, serious medical illness other than liver disease that might preclude completion of the study as hepatic failure, characterized by a history of ascites, hepatic encephalopathy and bleeding esophageal varices and pregnancy or lactating women. Only 230 patients had one or more than manifestation of $\mathrm{MC}$, and were tested for cryoglobulin levels in their serum. Eighty patients were positive for cryoglobulin levels, and were enrolled to complete our study. Full history taking and thorough clinical examination was done with stress on the manifestations of chronic liver illness and special emphasis 
on musculoskeletal, renal symptoms and skin lesions.

\section{Eighty patients enrolled in the study were classified into three groups:}

Group I: Thirty patients with cutaneous manifestations (ulcer, erythematous papules, purpura, hemorrhagic crusts, oral lichen planus and chronic urticaria). Skin punch biopsy was done for all patients.

Group II: Thirty patients with musculoskeletal manifestations. Only arthralgia and myalgia were observed in our study.

Group III: Twenty patients with renal manifestations as hematuria and proteinuria were put in this group. Renal biopsy for histopathological and immunohistochemical examination was done for all patients.

After taking written consents from all included patients, full history taking and thorough clinical examination was done with stress on the manifestations of chronic liver illness and special emphasis on musculoskeletal, renal symptoms and skin lesions.

- Eight milliliter of venous blood was collected from each patient and control under aseptic precautions, of which 2 $\mathrm{mL}$ of blood was placed in EDTA containing a vacutainer tube to obtain a complete blood picture in the automated hematology analyzer cell dyne-1800 (Abbott Diagnostics, Lake Forest, IL, USA). One milliliter was used for ESR test and five milliliters of blood was taken in a plain glass tube, and after clotting, the tube was centrifuged at 3,000 rpm for $5 \mathrm{~min}$. Then, the serum was separated for use in estimating liver function (including liver enzymes, albumin, bilirubin-total and direct, prothrombin time, prothrombin concentration, and INR), serum urea, serum creatinine, serum alfa fetoprotein, serum cholesterol, fasting blood sugar and RF using Cobas c311 automated chemistry analyzer (Roche Diagnostics, Mannheim, Germany). HBs Ag, HCVRNA levels, cryoglobulins, serum ANA and complement 3 (C3) and complement 4 (C4) serum assays were done. eGFR was calculated using the Mayo Clinic Quadratic Equation and urine analysis was done for the included patients.

- RF was measured using an immunoturbidimetric assay kit based on the immunological agglutination principle with enhancement of the reaction by latex, supplied by Roche Diagnostics, catalog No. c501/502. The normal reference range is $0-20 \mathrm{IU} / \mathrm{mL}$.

- HBs Ag testing were performed using commercially available assays (Abbott Laboratories, Abbot Park, IL, USA).

- HCV-RNA was detected by a PCR assay (Cobas Amplicor Roche Molecular Systems Inc., Branchburg, NJ, USA), and serum HCV-RNA levels were quantified by the Cobas Ampli Prep/Cobas TaqMan HCV-RNA assay (Roche Diagnostics) with a lower detection limit at $15 \mathrm{IU} / \mathrm{mL}$.

- The biochemical assessments of ANA, C3 and C4 were done using commercially available enzyme linked immunosorbent assay (ELISA) kits according to the manufacturer's protocol; these kits were supplied by Chongqing Biospes Co., Ltd., Chongqing, People's Republic of 
China, catalog no. (BYEK2304, BYEK1247, BYEK1247), respectively, using ELISA Multiskan EX Microplate Photometer [STAT FAX-2100; Thermo Scientific, Waltham, MA, USA]. The normal reference ranges for ANA, C3 and C4 are 0-1.5 U/ml, 90180 and $10-40 \mathrm{mg} / \mathrm{dL}$, respectively.

- Abdominal ultrasound was done for all enrolled patients.

- All the previously mentioned investigatory workups, in addition to the evaluation of the clinical manifestations of MC, were done to the included patients before starting therapy and 12 weeks after end of treatment.

The severity of the skin involvement was determined as follows: a score of 0 indicated the absence of skin lesions. A score of 1 , the presence of less than 10 purpura spots on the lower legs. A score of 2, the presence of more than 10 spots on the lower legs. A score of 3, the extension of the spots to the upper leg and/or the abdomen and a score of 4 , the presence of skin ulcers and/or gangrene.

To assess the severity of the arthralgia a clinical score was used: 0 indicated no arthralgia, 1 for occasional arthralgia, 2 for continuous arthralgia and 3 for intense arthralgia with impairment of movement.

In patients with renal involvement, the complete response was defined as the return to the normal level of the serum creatinine associated with the disappearance of proteinuria. A partial response was defined as the decrease of creatinine and proteinuria by more than $50 \%$ and a minimal response as the decrease of creatinine and of proteinuria by less than $50 \%$. The decrease of proteinuria by less than $10 \%$ was considered as no response.

All patients were diagnosed and treated with sofosbuvir $400 \mathrm{mg}$ and daclatasvir 60 $\mathrm{mg} \pm$ ribavirin $(800-1,200 \mathrm{mg}$ ) once daily for 3 months. Patients were treated according to the Egyptian protocol for treatment of chronic HCV virus infection, which depends on the European Association for the Study of the Liver 2018 guidelines for $\mathrm{HCV}$ infection treatment.

The judging points regarding the efficacy of sofosbuvir and daclatasvir in improving the condition of HCV-MC patients were as follows:

i. Clinical improvement of the presenting cryglobulinemic related manifestations,

ii. SVR, which is defined as undetectable HCV-RNA levels 12 weeks after end of treatment and,

iii.Disappearance of cryoglobulins in serum. According to the presence or absence of the 3 previously mentioned criteria, the effect of the used DAAs can be classified into 3 types: complete response if all 3 parameters have been achieved, partial response if SVR with either of the remaining 2, and no response if none of the 3 parameters have been achieved.

\section{Statistical methods:}

Data Management and Analysis: The collected data was revised, coded, tabulated and introduced to a PC using Statistical package for the Social Sciences (SPSS 20). Data was presented and suitable analysis was done according to 
the type of data obtained for each parameter.

\section{Descriptive statistics:}

Mean, Standard deviation ( \pm SD) for numerical data, frequency and percentage of non-numerical data. Analytical statistics:

1 Paired t-test was used to assess the statistical significance of the difference between two means measured twice for the same study group.

2. McNemar test was used assess the statistical significance of the difference between a qualitative variable measured twice for the same study group.
3. Wilcoxon Signed Rank test: nonparametric test was used to compare repeated measurements for the name group when the data are nonparametric.

4. One-way ANOVA should be used to compare more than 2 measurements.

5. Chi-square test was used to compare quantitative data. $\mathrm{P} \leq 0.05$ was considered significant.

\section{RESULTS}

The study was completed on 80 patients who proved to have MC by testing positive for serum cryoglobulins.
The mean age of the included HCV-MC patients was 54.2 years $\pm 8.4 \mathrm{SD} ; 44$ $(55 \%)$ of them were females (Table 1).

Table (1): Age and gender distribution in all groups

\begin{tabular}{|c|c|c|c|c|c|c|c|c|}
\hline \multirow{2}{*}{\multicolumn{2}{|c|}{$\mathrm{Parameters}_{\text {Proups }}$ G }} & \multicolumn{2}{|c|}{$\begin{array}{l}\text { Cutaneous } \\
(\mathrm{N}=30)\end{array}$} & \multicolumn{2}{|c|}{$\begin{array}{c}\text { Musculoskeletal } \\
(\mathrm{N}=30)\end{array}$} & \multicolumn{2}{|c|}{$\begin{array}{c}\text { Renal } \\
(\mathrm{N}=20)\end{array}$} & P-value \\
\hline & & \multicolumn{2}{|c|}{ Mean \pm SD } & \multicolumn{2}{|c|}{ Mean \pm SD } & \multicolumn{2}{|c|}{ Mean \pm SD } & \\
\hline \multicolumn{2}{|c|}{ Age } & \multicolumn{2}{|c|}{$55.07 \pm 8.56$} & \multicolumn{2}{|c|}{$51.43 \pm 8 .^{33}$} & \multicolumn{2}{|c|}{$52.15 \pm 6.65$} & 0.195 \\
\hline & & $\mathrm{N}$ & $\%$ & $\mathrm{~N}$ & $\%$ & $\mathrm{~N}$ & $\%$ & \\
\hline \multirow{2}{*}{ Gender } & Female & 20 & $66.7 \%$ & 13 & $43.3 \%$ & 11 & $55.0 \%$ & \multirow{2}{*}{0.192} \\
\hline & Male & 10 & $33.3 \%$ & 17 & $56.7 \%$ & 9 & $45.0 \%$ & \\
\hline
\end{tabular}

$\mathrm{N}=$ Number, $\mathrm{SD}=$ Standard deviation.

From the relative frequencies of the presenting clinical manifestations purpuric papules of the lower extremities was the most frequent cutaneous lesion 24/30 $(80 \%)$ and arthralgia was the most frequent in musculoskeletal manifestations 27/30 (90\%) and Diffuse Membranoproliferative glomerulonephritis was the most frequent lesions in patients with renal manifestations 18/20 (90\%).Regarding the clinical effects of sofosbuvir and daclatasvir therapy on HCV-MC, the patients with cutaneous manifestations showed significant improvement in their clinical manifestations, $50 \%$ of patients with purpuric papules of the lower extremities, $100 \%$ of patients with hemorrhagic crusts and/or ulcers, lichen planus and Chronic urticaria. Also, 
KARIM S. EL-NOEMANY et al.,

patients with musculoskeletal manifestations showed significant improvement in their clinical manifestations, $74 \%$ and $67 \%$ in patients with arthralgia and myalgia respectively.Regarding patients with cutaneous manifestations, leukocytoclastic

vasculitis with cryoglobulin deposits was the most frequent pathological manifestation (70\%), lymphocytic infiltrate $(26.7 \%)$ and urticarial vasculitis $(3.3 \%)$, and all had significant improvement after treatment with sofosbuvir and daclatasvir (Table 2).

Table (2): Clinical presentations, frequency of affected patients and frequency of improved patients in cutaneous and musculoskeletal manifestations

\begin{tabular}{|c|c|c|c|c|}
\hline \multicolumn{2}{|c|}{ Frequency } & $\begin{array}{c}\text { Affected } \\
\text { patients (\% of } \\
\text { all group } \\
\text { patients) }\end{array}$ & $\begin{array}{c}\text { Improved } \\
\text { patients (\% of } \\
\text { affected } \\
\text { patients with } \\
\text { the same sign) }\end{array}$ & P \\
\hline \multirow{7}{*}{$\begin{array}{c}\text { Cutaneous } \\
\text { manifestations }\end{array}$} & $\begin{array}{c}\text { purpuric papules of } \\
\text { the lower } \\
\text { extremities }\end{array}$ & $24(80 \%)$ & $12(50 \%)$ & 0.02 \\
\cline { 2 - 5 } & $\begin{array}{c}\text { hemorrhagic crusts, } \\
\text { and/or ulcers }\end{array}$ & $3(10 \%)$ & $3(100 \%)$ & 0.001 \\
\cline { 2 - 5 } & lichen planus & $1(3.33 \%)$ & $1(100 \%)$ & 0.001 \\
\cline { 2 - 5 } & Chronic urticarial & $2(6.66 \%)$ & $2(100 \%)$ & 0.001 \\
\hline \multirow{2}{*}{$\begin{array}{c}\text { Musculoskeletal } \\
\text { manifestations }\end{array}$} & Total & $30(100 \%)$ & $18(60 \%)$ & 0.001 \\
\cline { 2 - 5 } & Arthralgia & $27(90 \%)$ & $20(74 \%)$ & 0.001 \\
\cline { 2 - 5 } & myalgia & $3(10 \%)$ & $2(67 \%)$ & 0.001 \\
\hline
\end{tabular}

According to pathological presentations in patients with renal manifestations, diffuse membranoproliferative glomerulonephritis

was improved on only $16.6 \%$ of affected patients with no significant difference before and after treatment (Table 3).

Table (3): Pathological presentations, frequency of affected patients and frequency of improved patients with cutaneous and renal manifestations

\begin{tabular}{|c|c|c|c|c|}
\hline \multicolumn{2}{|c|}{ Frequency } & $\begin{array}{c}\text { Affected } \\
\text { patients (\% } \\
\text { of all group } \\
\text { patients) }\end{array}$ & $\begin{array}{c}\text { Improved } \\
\text { patients (\% of } \\
\text { affected } \\
\text { patients with } \\
\text { same } \\
\text { pathology) }\end{array}$ & $\mathrm{P}$ \\
\hline \multirow{4}{*}{$\begin{array}{c}\text { Cutaneous } \\
\text { manifestations }\end{array}$} & $\begin{array}{c}\text { Leukocytoclastic } \\
\text { vasculitis with } \\
\text { cryoglobulin deposits }\end{array}$ & $21(70 \%)$ & $12(57 \%)$ & 0.001 \\
\cline { 2 - 5 } & Lymphocytic infiltrate & $8(26.7 \%)$ & $4(50 \%)$ & 0.001 \\
\cline { 2 - 5 } & Urticarial vasculitis & $1(3.3 \%)$ & $1(100 \%)$ & 0.001 \\
\cline { 2 - 5 } & Total & $30(100 \%)$ & $17(57 \%)$ & 0.001 \\
\hline $\begin{array}{c}\text { Renal } \\
\text { manifestations }\end{array}$ & $\begin{array}{c}\text { Diffuse } \\
\text { Membranoproliferative } \\
\text { glomerulonephritis }\end{array}$ & $18(90 \%)$ & $3(16.6 \%)$ & 0.191 \\
\hline
\end{tabular}




\begin{tabular}{|c|c|c|c|c|}
\hline & $\begin{array}{c}\text { Tubulo-interstitial } \\
\text { nephritis }\end{array}$ & $1(5 \%)$ & 0 & $>0.05$ \\
\cline { 2 - 5 } & $\begin{array}{c}\text { Focal and segmental } \\
\text { glomerulosclerosis }\end{array}$ & $1(5 \%)$ & 0 & $>0.05$ \\
\cline { 2 - 5 } & Total & $20(100 \%)$ & $3(15 \%)$ & 0.251 \\
\hline
\end{tabular}

There was significant difference regarding response rates in all patients with mixed cryoglobulinemia following treatment with sofosbuvir and daclatasvir. In cutaneous manifestation group, 18 (60\%), 99 (30\%), and $3(10 \%)$ patients had complete response, partial response and sustained virological response (SVR) only respectively. In musculoskeletal manifestation group, 22 (73.33\%), 6 (20\%) and 2 (6.66\%) patients had complete response, partial response and only SVR respectively. In group of renal extrahepatic manifestation, the response was complete in $3(15 \%)$ patients, partial in $12(60 \%)$ patients and SVR only in 5 (25\%) patients (Table 4).

Table (4): Response rates in all patients with mixed cryoglobulinemia following treatment with DAAs

\begin{tabular}{|c|c|c|c|c|c|}
\hline Response & $\begin{array}{l}\text { Cutaneous } \\
\text { group } \\
(\mathrm{N}=30) \\
\end{array}$ & $\begin{array}{l}\text { Musculoskeletal } \\
\text { group }(\mathrm{N}=30)\end{array}$ & $\begin{array}{l}\text { Renal } \\
\text { group } \\
(\mathrm{N}=20)\end{array}$ & $\begin{array}{c}\text { Total } \\
(\mathrm{N}=80)\end{array}$ & $P$ \\
\hline Complete & 18 & 22 & 3 & 43 & \multirow{3}{*}{$\begin{array}{c}< \\
0.001\end{array}$} \\
\hline Partial & 9 & 6 & 12 & 27 & \\
\hline SVR only & 3 & 2 & 5 & 10 & \\
\hline
\end{tabular}

SVR = Sustained virological response.

The effect of sofosbuvir and daclatasvir therapy on serum cryoglobulin levels showed that $90 \%$ of mixed cryoglobulinimic patients with cutaneous manifestations, $93.3 \%$ of patients with musculoskeletal manifestations and $75 \%$ patients with renal manifestations turned to negative after treatment. Our study also, showed negativity of serum cryoglobulin in $87.5 \%$ of all included patients with extrahepatic manifestations post-therapy with sofosbuvir and daclatasvir (Table 5).

Table (5): Comparison of serum cryoglobulin before and after treatment with DAAs in patients group with cutaneous, musculoskeletal and renal manifestations

\begin{tabular}{|c|c|c|c|c|c|c|}
\hline \multicolumn{2}{|c|}{ Cryoglobulin2 } & Negative & Positive & Total & P \\
\hline Manifestations & Cryoglobulin1 & Positive & $27(90 \%)$ & $3(10 \%)$ & $\begin{array}{c}30 \\
(100 \%)\end{array}$ & 0.001 \\
\hline Musculoskeletal & Cryoglobulin1 & Positive & $\begin{array}{c}28 \\
(93.33 \%)\end{array}$ & $\begin{array}{c}2 \\
(6.67 \%)\end{array}$ & $\begin{array}{c}30 \\
(100 \%)\end{array}$ & 0.001 \\
\hline Renal & Cryoglobulin1 & Positive & $15(75 \%)$ & $5(25 \%)$ & $\begin{array}{c}20 \\
(100 \%)\end{array}$ & 0.001 \\
\hline Whole sample & Cryoglobulin1 & Positive & $\begin{array}{c}70 \\
(87.5 \%)\end{array}$ & $\begin{array}{c}10 \\
(12.5 \%)\end{array}$ & $\begin{array}{c}80 \\
(100 \%)\end{array}$ & 0.001 \\
\hline
\end{tabular}

Cryoglobulin1 = serum cryoglobulin level before therapy, Cryoglobulin2 = serum cryoglobulin level posttherapy. 
Comparison of laboratory investigations done before treatment with DAAs and after treatment in patients group with cutaneous manifestations and musculoskeletal, there was significant difference as regard RF, C4 and ANA with p- value of 0.001 or less. Laboratory measures among HCV-MC with renal manifestations had significant decrease in $\mathrm{RF}$ and significant increase in $\mathrm{C} 4$ posttherapy with DAAs with $\mathrm{p}$ - value of $<0.001$, but there was non-significant difference regarding ANA post-treatment (Table 6).

Table (6): Data of investigations before and after treatment with DAAs in different groups

\begin{tabular}{|c|c|c|c|c|}
\hline \multirow{3}{*}{ Proups } & $\begin{array}{c}\text { Laboratory } \\
\text { investigation }\end{array}$ & Before treatment & After treatment & $\begin{array}{c}\text { Wilcoxon } \\
\text { Signed } \\
\text { Rank test }\end{array}$ \\
\cline { 3 - 5 } Cutaneous & RF & $19.1(17.4-22.3)$ & $5.25(3-6)$ & $<0.001$ \\
\cline { 2 - 5 } & C4 & $18.6(15.6-20.9)$ & $26(21-33)$ & $<0.001$ \\
\cline { 2 - 5 } & ANA & $0.25(0.1-0.4)$ & $0(0-0.3)$ & 0.002 \\
\hline \multirow{3}{*}{ Musculoskeletal } & RF & $20.8(16.5-24.5)$ & $4.55(3.5-6.3)$ & $<0.001$ \\
\cline { 2 - 5 } & C4 & $20.6(19.9-21.3)$ & $30.8(27.8-34)$ & $<0.001$ \\
\cline { 2 - 5 } & ANA & $0.2(0-0.3)$ & $0(0-0.2)$ & 0.002 \\
\hline \multirow{3}{*}{ Renal } & RF & $23.35(19.8-25.1)$ & $5.5(4.5-6.5)$ & $<0.001$ \\
\cline { 2 - 5 } & C4 & $15.7(7.7-19.2)$ & $20.1(10.8-24.5)$ & $<0.001$ \\
\cline { 2 - 5 } & ANA & $0.3(0.1-0.5)$ & $0(0-0.5)$ & 0.382 \\
\hline
\end{tabular}

$\mathrm{RF}=$ rheumatoid factor, $\mathrm{C} 4=$ complement $4, \mathrm{ANA}=$ antinuclear antibody, IQR $=$ Interquartile Range.

There was also significant increase in C3 levels from $69.24 \pm 6.93$ to $129.27 \pm 18.93$, from $74.07 \pm 5.39$ to $126.29 \pm 17.12$ and from $72.68 \pm 9.38$ to $113.60 \pm 18.30$ in patients with cutaneous, musculoskeletal and renal manifestations, respectively and significant increase in eGFR in patients with renal manifestations (Table 7).

Table (7): Data of investigations before and after treatment with DAAs in different groups

\begin{tabular}{|c|c|c|c|c|}
\hline Parameters & \multirow{2}{\text{Laboratory}}{$\begin{array}{c}\text { Paroups } \\
\text { investigation }\end{array}$} & Before treatment & After treatment & Paired t test \\
\cline { 3 - 5 } & C3 & $69.24 \pm 6.93$ & $129.27 \pm 18.93$ & 0.001 \\
\hline Cutaneous & C3 & $74.07 \pm 5.39$ & $126.29 \pm 17.12$ & 0.001 \\
\hline Musculoskeletal & C3 & $72.68 \pm 9.38$ & $113.60 \pm 18.30$ & 0.001 \\
\hline \multirow{2}{*}{ Renal } & eGFR & $49.70 \pm 8.12$ & $65.80 \pm 12.45$ & 0.001 \\
\cline { 2 - 5 } & &
\end{tabular}

$\mathrm{C} 3=$ complement 3, eGFR $=$ estimated glomerular filtration rate, $\mathrm{SD}=$ Standard deviation.

\section{DISCUSSION}

$\mathrm{HCV}$ is well known for having high immunogenic capacity, converting $\mathrm{HCV}$ infection in a systemic disease. Following the identification of $\mathrm{HCV}$ as the largely prevalent etiologic agent of MC, researchers in several studies have evaluated the therapeutic efficacy of antiviral drugs such as IFN- $\alpha$, with or without ribavirin, in this condition. These 
studies consistently reported lower rates of SVR in HCV-positive patients with MC than in those without MC. In addition, IFN-based regimens were characterized by severe adverse events, often leading to therapy discontinuation (Dammacco and Sansonno, 2013). Our study found that $\mathrm{HCV}$ patients proven to have MC, showed female predominance in patients with cutaneous and renal manifestations but male predominance in patients with musculoskeletal predominance, and this was in line with Mohammed and his Colleagues (2010), whom reported that cryoglobulinemia was significantly more common in the female population with $\mathrm{HCV}$. Also, there was no significant difference regarding age in all groups.

Serum cryoglobulins were found in approximately $30-40 \%$ of $\mathrm{HCV}$ patients, with 5 to $30 \%$ of these patients manifesting with MCS. The pathophysiology is unclear, with both direct and indirect theories proposed. The direct theory, supported by evidence that $\mathrm{HCV}$ is lymphotropic and that the cryoprecipitate contains high concentrations of viral genome, beside that $\mathrm{HCV}$ induces $\mathrm{B}$ cells to produce immunoglobulins. Alternatively, the indirect theory proposes that the virus provokes $\mathrm{MC}$ via chronic immune stimulation (Cacoub et al., 2016). In our study, only $12.7 \%$ of $\mathrm{HCV}$ patients had positive serum cryoglobulin, the difference may be due to sampling and the race of patients.

In the present study, purpuric papules (80\%) were the most frequent sign in $\mathrm{MC}$ patients with cutaneous manifestations in agreement with Dammacco and his Colleagues (2013) whom reported that
Cryoglobulinemic vasculitis was most evident on the skin as palpable purpura, seen in virtually all patients with cryoglobulinemia. Arthralgias were a common complaint of $\mathrm{HCV}$-infected patients in the current study and were reported in $90 \%$ of MC patients with musculoskeletal symptoms, these results came in agreement with Palazzi and his Colleagues (2016). Proteinuria was the frequent sign $(75 \%)$ in MC patients with renal manifestations in our study, and also, some patients manifested with macroscopic hematuria (5\%), nephrotic syndrome $(10 \%)$ and nephritic syndrome $(10 \%)$. These results were in accordance with the findings of Cacoub and his Colleagues (2016) whom reported that renal manifestations cover a variety of disorders ranging from slightly proteinuria and hematuria, to nephrotic and nephritic syndromes, as well as renal insufficiency in a lesser extent in HCV-related MC patients suffering from kidney disease.

Diffuse membranoproliferative glomerulonephritis (MPGN) was the most common pathological finding in $\mathrm{MC}$ patients with renal affection 18/20 (90\%), in agreement with Dammacco and his Colleagues, whom reported that the most common renal manifestations of $\mathrm{HCV}$ infection were essential mixed cryoglobulinemia (MC) leading to membranoproliferative glomerulonephritis (MPGN), MPGN without cryoglobulinemia, and membranous glomerulonephritis. In our patients with MC cutaneous manifestations, leukocytoclastic vasculitis (LCV) with cryoglobulin deposits was found in about $70 \%$ of patients, lymphocytic infiltrate and urticarial vasculitis in $26.7 \%$, and $3.3 \%$ respectively. At SVR12, there was 
improvement in 57\%, 50\% and $100 \%$ of patients respectively. These results are in agreement with Rutledge and his Colleagues (2018), whom reported that LCV was detected in 50\% of skin biopsy specimens in HCV-MC patients.

Because the activity of MC usually correlates with viremia, therapy should be directed toward the potential causal agent. The efficacy and safety of all oral DAAs therapyin HCV-MC are largely unknown, Gragnani et al. (2015) and few studies investigated the efficacy of sofosbuvirbased DAA regimens for HCV patients generally and for HCV-MC patients specifically. The results of the current study pertaining to the therapeutic efficacy of the combined use of sofosbuvir and daclatasvir as oral DAAs, revealed that $100 \%$ of patients had SVR12 and clearance of cryoglobulins in $87.5 \%$ of patients in all groups, with significant improvements in eGFR ( in renal manifestations group), CBC, AST, ALT, total bilirubin, direct bilirubin, serum albumin, ESR and AFP in all groups, with $54 \%$ of the included patients achieved a complete response, $34 \%$ a partial response and $12 \%$ had only SVR response. This indicated the higher therapeutic efficacy and safety of sofosbuvir and daclatasvir in managing HCV-MC. In agreement with these findings, Sise et al. (2016) reported that $83 \%$ of HCV-MC patients showed SVR12 rates for sofosbuvir based DAA regimens. Also, our findings were in line with Bonacci et al. (2017), and Saadoun. et al. (2017) whom reported an abrupt decay of HCV-RNA with DAAs with a rapid improvement of the clinical manifestations of MC that may allow the reduction or even cessation of the traditional immunosuppressive therapy.
Lauletta and her Colleagues (2017) reported that at SVR12, cryoglobulins disappeared or decreased by at least 50\% in $77.3 \%$ of their patients. Another Egyptian study found that the combined use of sofosbuvir and daclatasvir as oral DAAs revealed $100 \%$ SVR12 and clearance of cryoglobulins, with significant improvements in Child-Pugh score, liver fibroscan status, hemoglobin levels, platelet counts, liver functions, and eGFR and creatinine levels, with $87 \%$ of the included patients showing a complete response and $13 \%$ a partial response without any side effects (Hassan et al., 2018). Our findings revealed significantly higher RF with significantly lower $\mathrm{C} 3$ and C4 serum levels among the included HCV-MC in all groups, with significant improvements in their level following DAAs. In line with our data, Gragnani et al. (2016) and Hassan et al. (2018) had reported similar findings. On another study, RF and C4 levels are less influenced by DAAs within the short period of 12 weeks after stopping therapy and may represent independent markers not only of clinical activity but also of persistently activated B-cell clones (Lauletta G. et al., 2017).

Lauletta and herColleagues (2017) reported that at SVR12, cryoglobulins disappeared or decreased by at least $50 \%$ in $77.3 \%$ of patients in patients treated with DAAs, serum cryoglobulins disappeared in $90 \%, 93 \%$ and $75 \%$ of patients with extrahepatic cutaneous, musculoskeletal and renal manifestations after treatment with DDAs despite SVR12 was $100 \%$. The difference between us and mentioned study may be due to different sampling of patients, genotype, and DAAs regimen used in the treatment. 


\section{CONCLUSION}

DAAs, in the form of Sofosbuvir/Daclatasvir $\quad \pm \quad$ Ribavirin regimen, were a treatment of choice for $\mathrm{HCV}$ infection and should be considered in cases of $\mathrm{HCV}-\mathrm{MC}$ as they were associated with clinical improvement in most patients.

\section{DISCLOSURE}

The authors report no conflicts of interest in this work.

\section{REFERENCES}

1. Bhavtosh D and George Y. Wu. (2015): Dermatologic Extrahepatic Manifestations of Hepatitis C. Journal of Clinical and Translational Hepatology, 3:127-133.

2. Bonacci M, Lens S, Londono MC, Marino Z, Cid MC, Ramos-Casals M, Sanchez-Tapias JM, Forns $\mathrm{X}$ and Hernandez-Rodriguez J. (2017): Virologic, clinical, and immune response outcomes of patients with hepatitis C virus-associated cryoglobulinemia treated with direct-acting antivirals. Clin Gastroenterol Hepatol., 15(4):575-583.

3. Cacoub P, Comarmond C, Domont F, Savey L, Desbois AC and Saadoun D. (2016): Extrahepatic manifestations of chronic hepatitis $\mathrm{C}$ virus infection. Ther Adv Infect Dis., 3(1):3-14.

4. Dammacco F and Sansonno D. (2013): Therapy for hepatitis C virus-related cryoglobulinemic vasculitis. $\mathrm{N}$ Engl J Med., 369:1035-45.

5. Gragnani L, Fognani E, Piluso A, Boldrini B, Urraro T, Fabbrizzi A, Stasi C, Ranieri J, Monti M, Arena U, Iannacone $\mathrm{C}$, Laffi $\mathrm{G}$, Zignego $\mathrm{AL}$ and MaSVE Study Group. (2015): Long-term effect of HCV eradication in patients with mixed cryoglobulinemia: a prospective, controlled, open-label, cohort study. Hepatology, 61(4):1145-53.

6. Gragnani L, Visentini M, Fognani E, Urraro T, De Santis A, Petraccia L, Perez M, Ceccotti G, Colantuono S, Mitrevski M, Stasi C, Del Padre M, Monti M, Gianni E, Pulsoni A, Fiorilli M, Casato $M$ and Zignego AL. (2016): Prospective study of guideline-tailored therapy with direct-acting antivirals for hepatitis $\mathrm{C}$ virus-associated mixed cryoglobulinemia. Hepatology, 64(5):1473-1482.

7. Hassan AM, Osman HA, Mahmoud HS, Hassan MH, Hashim AA and Ameen HH. (2018): Sofosbuvir-daclatasvir improves hepatitis $\mathrm{C}$ virus- induced mixed cryoglobulinemia: Upper Egypt experience. Infect Drug Resist., 11:895901.

8. Lauletta G, Russi S, Pavone F, Vacca A and Dammacco F. (2017): Direct-acting antiviral agents in the therapy of hepatitis $\mathrm{C}$ virus-related mixed cryoglobulinaemia: a single-centre experience. Arthritis Res Ther., 19(1):74.

9. Mazzaro C, Monti G, Saccardo F, Zignego AL, Ferri $C$ and De Vita $S$. (2011): Efficacy and safety of peginterferon alfa- $2 b$ plus ribavirin for $\mathrm{HCV}$ - positive mixed cryoglobulinemia: a multicentre open-label study. Clin Exp Rheumatol., 29(6):933-941.

10.Mohammed RH, EIMakhzangy HI and Gamal A. (2010): Prevalence of rheumatologic manifestations of chronic hepatitis $\mathrm{C}$ virus infection among Egyptians. Clin Rheumatol., 29(12):13731380.

11.Palazzi C, D'Amico E, D'Angelo S, Gilio $M$ and Olivieri I (2016): Rheumatic manifestations of hepatitis $\mathrm{C}$ virus chronic infection: Indications for a correct diagnosis. World J Gastroenterol., 22(4): 1405-1410. 
12.Ramos-Casals $M$, Zignego AL, Ferri $C$, Brito-Zerón P, Retamozo S, Casato M, Lamprecht P, Mangia A, Saadoun D, Tzioufas AG, Younossi ZM and Cacoub P. (2017): International Study Group of Extrahepatic Manifestations related to $\mathrm{HCV}$ (ISG-EHCV). Evidence-based recommendations on the management of extrahepatic manifestations of chronic hepatitis C virus infection. J Hepatol., 66(6):1282-1299.

13.Rutledge SM, Chung RT and Sise ME. (2018): Treatment of hepatitis $C$ virus infection in patients with mixed cryoglobulinemic syndrome and cryoglobulinemic glomerulonephritis. Hemodial Int., (1):S81-S96.

14.Saadoun D, Pol S, Ferfar Y, Alric L, Hezode C, Si Ahmed SN, de Saint Martin L, Comarmond C, Bouyer AS, Musset L, Poynard T, Resche Rigon M and Cacoub P. (2017): Efficacy and
Safety of Sofosbuvir Plus Daclatasvir for Treatment of HCV-Associated Cryoglobulinemia Vasculitis. Gastroenterology, 153(1):49-52.e5.

15.Sise ME, Bloom AK, Wisocky J, Lin MV, Gustafson JL, Lundquist AL, Steele D, Thiim M, Williams WW, Hashemi N, Kim AY, Thadhani R and Chung RT. (2016): Treatment of hepatitis C virus-associated mixed cryoglobulinemia with direct-acting antiviral agents. Hepatology., 63(2):40817.

16. Terrier $B$ and Cacoub P. (2013): Renal involvement in HCV-related vasculitis. Clin Res Hepatol Gastroenterol., 37(4):334-9. 


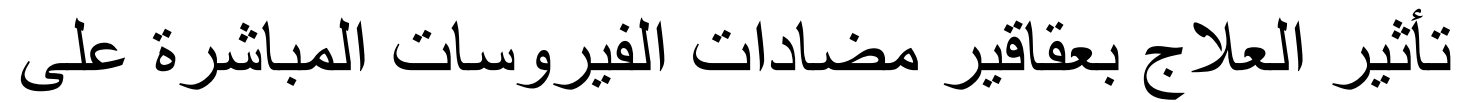

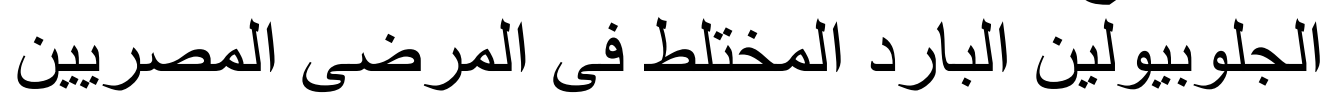

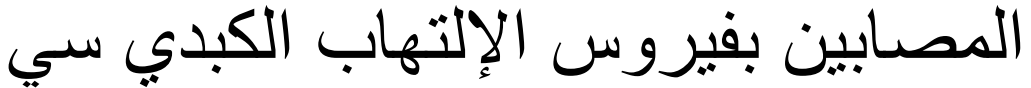

كريم صبحى النعماني، محمد حسن النادري، سيد فاروق محمد، محمد محمود عبدالحليم قسم الكبد والجهاز الهضمى والأمراض المعدية، كلية الطب، جامعة الأزهر، القاهرة

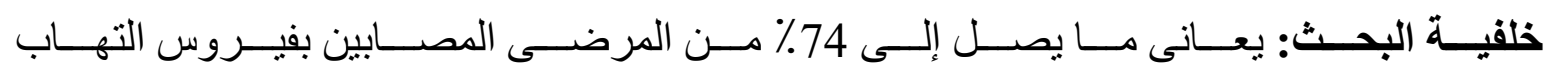

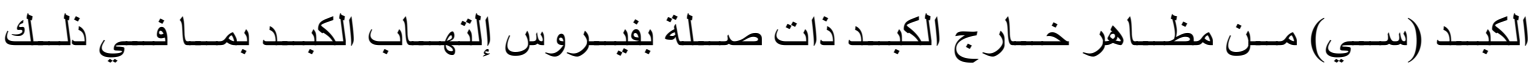

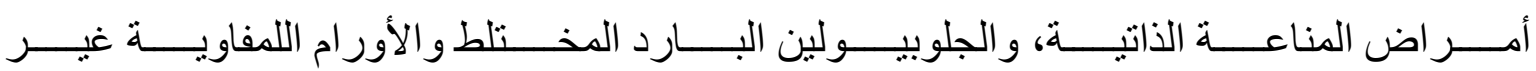

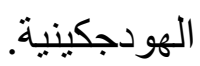

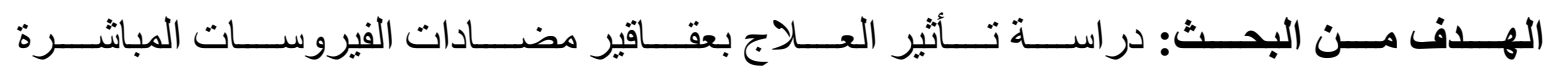

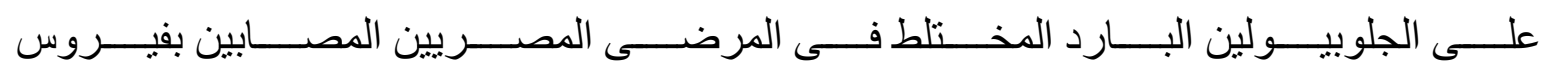
الإلتهاب الكبدي (سي).

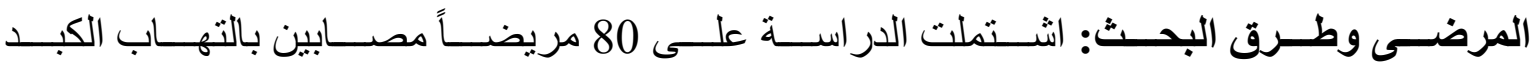

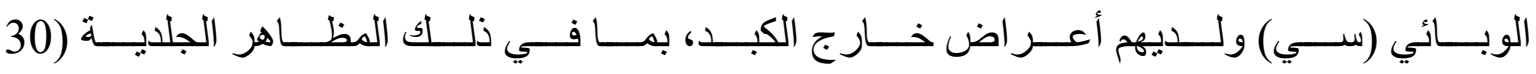

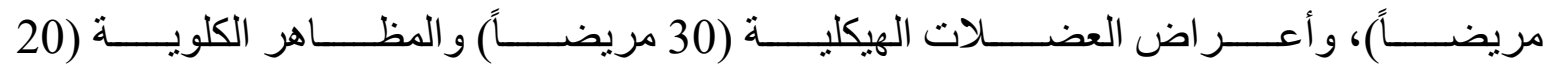

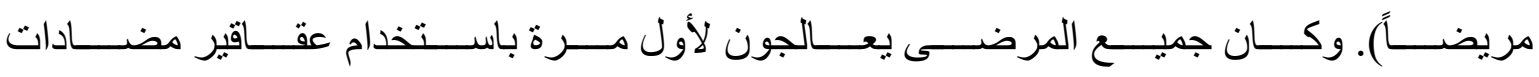
الفيروسات المباثرةتظام سوفوسبوفير /دكلاتاسفير \pm ريبافيرين.

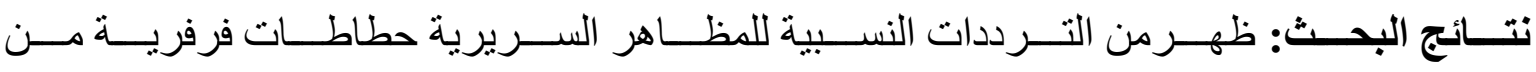

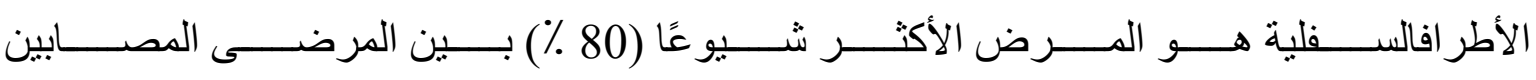

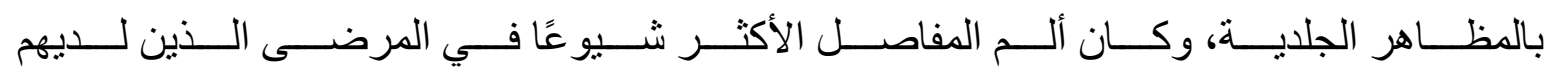

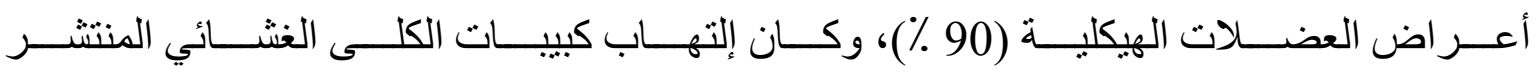

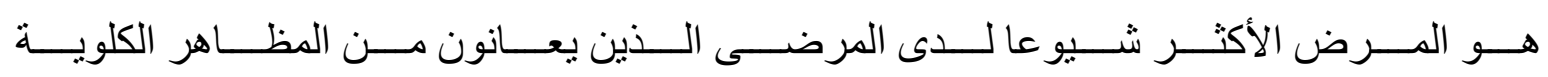

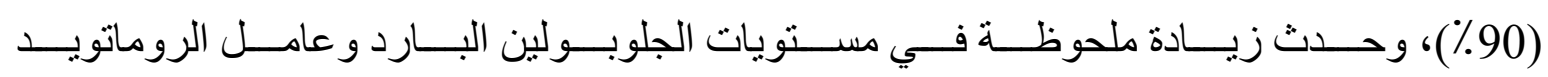

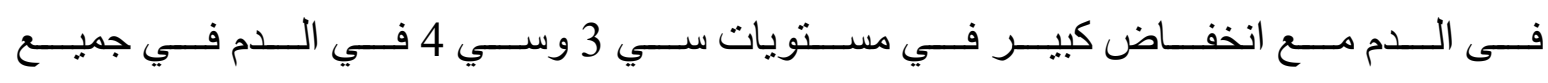

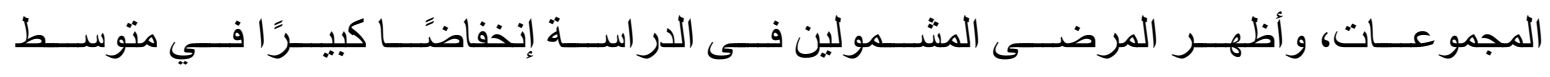

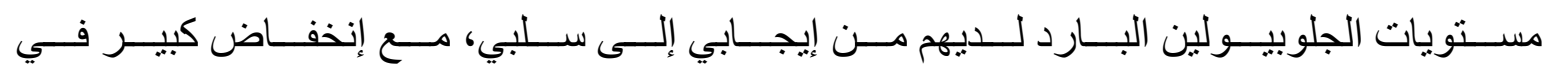




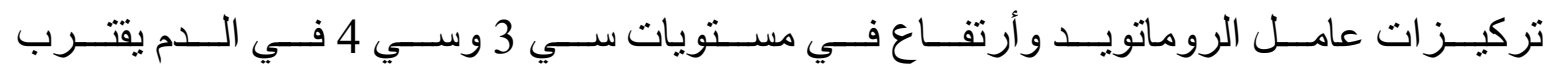

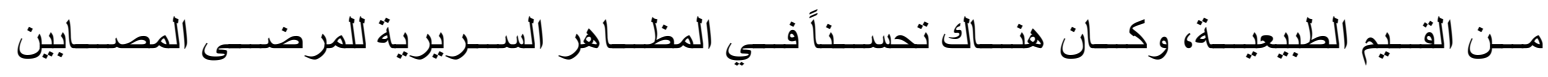

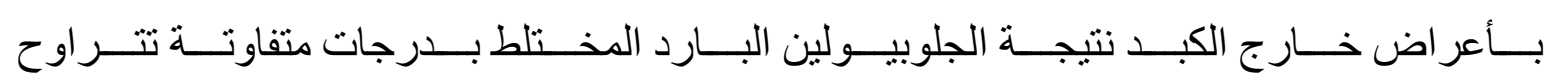

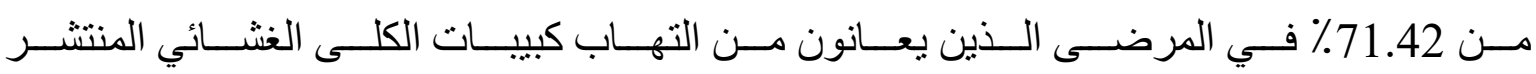

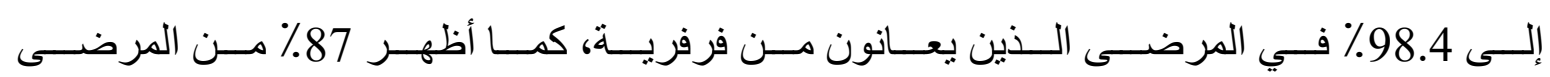

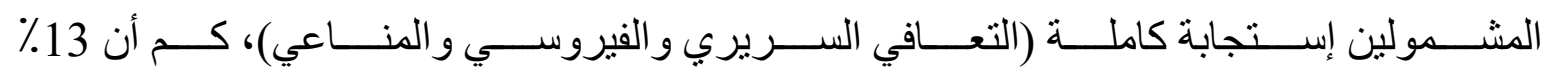

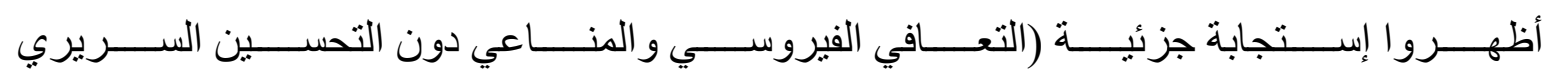
للمظاهر المرتبطة بالجليوبولين البارد فى الدم).

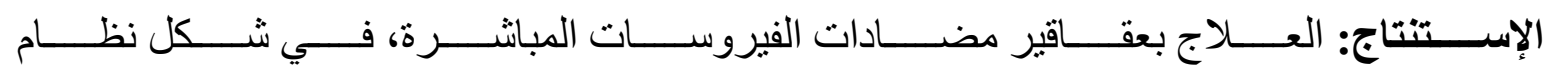

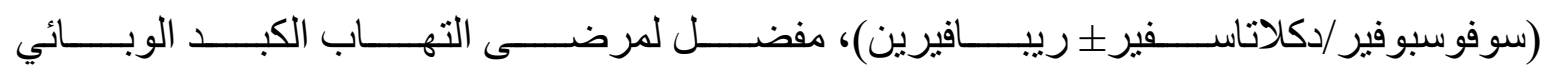

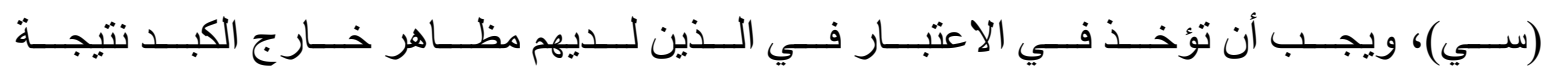
الجلوبيولين البارد المختلط لأنها مرتبطة بالتحسن السريري في معظم المرضى. 